\title{
A Methodological Probe to Aeronautical English Vocabulary Instruction
}

\author{
Aiguo Wang \\ College of Foreign Languages, Civil Aviation University of China, Tianjin, China. \\ Email: kevinerau@yahoo.com \\ Received October 20 $0^{\text {th }}, 2011$; revised November 20 $0^{\text {th }}, 2011$; accepted November $30^{\text {th }}, 2011$.
}

\begin{abstract}
Students' knowledge of words impacts their achievement in all areas of the curriculum because words are necessary for communicating the content. Aeronautical English vocabulary is a major difficulty which impedes students' progress in EAP (English for Academic Purposes) learning (usually conducted in native English countries) or ESP (English for Specific Purposes). The paper introduces readers to the status quo of aeronautical English vocabulary teaching in P. R. China and some specifics of it in classroom activities so that EAP/ESP teachers can have a better idea of ESL teaching with regard to width and depth of aeronautical English vocabulary knowledge.
\end{abstract}

Keywords: Aeronautical English Vocabulary, Classroom Activity, Teaching Methods

\section{Introduction}

Science and aeronautical technology are committed to the universal. Aircraft, airports, lighting systems, control towers, terminal buildings tend increasingly to be world styles. In aeronautical or aviation sector our sense of differences in culture and technology diminishes. Take the radiotelephony (RT) language for example, it is based on the English language with loans from other cultures and languages. The essence of teaching aeronautical English is the spread of modern science and technology. And aeronautical English vocabulary is a symbol and a collection of technological developments in aeronautical/aviation industry, a linkage network of global transportation. Since the aeronautical industry consists of different codes and communities of practice, and displays discursive features and factors of difficulty for students of aeronautical English (e.g. condensed grammar in skytalk, specialised phraseological units in engineering technolect, simplified English in the aircraft maintenance sector, etc.), the numerous intralexical factors that affect aeronautical vocabulary learning include pronounceability, orthography, length, morphology, similarity of lexical forms, grammar, and semantic features. These difficulties are derived from the multiplicity and variety of aeronautical communities and pose great challenges for aeronautical and/or aviation university students with regard to the meaning and form of a word, its pronunciation, spelling, recognition and retention. Blue says that EAP has two divisions-English for General Academic Purposes (EGAP) and English for Specific Academic Purposes (ESAP) (Blue, 1988). However, neither EGAP nor ESAP seems entirely suitable for the Chinese context. What we practice is like a presessional course for students' further study abroad. Therefore the method we use is undoubtedly borne with Chinese characteristics.

According to a survey made in Civil Aviation University of China, $83 \%$ students admit that vocabulary is an important factor in learning the English language. Our research (see appendix I) indicates that vocabulalry is the number one obstacle

\footnotetext{
*This paper is a partial fulfilment of our research project granted by Tianjin Education Bureau and prepares for further research at national level.
}

in reading comprehension, followed by grammar and background knowledge; greatest barrier in listening comprehension, followed by speaking speed and accent, greatest impediment to oral and written expression, followed by organizing viewpoint and grammar. The paper explores methods and tactics of teaching and learning aeronautical English vocabulalry with reference to lexicology, such as word formation through compounding and affixation, in the hope that the methods and tactics can be transfered to other contexts of language instruction. The purpose of aeronautical English vocabulary instruction is three fold: 1) to develop students' capability of using English as a medium to exchange ideas on specific subjects; 2) to enlarge students' English vocabulary in respective field of aviation/aeronautical industry; and 3) to help students grasp knowledge and skills within the context of aeronautical English.

\section{Systematic Recognition of Aeronautical English Vocabulary}

Halliday ever says that "language varies as its function varies; it differs in different situations." Aeronautical English vocabulary abounds in a large scope of aeronautical and/or aviation sectors: 1) aviation history and culture; 2) aviation materials; 3 ) aircraft structure and systems (control system, lighting system, electrical system, electronics, hydraulic system, power-plant, air conditioning, landing gears, fuel and water.); 4) airport (runway construction, coding, environment, facilities, management and operation, fire fighting, terminal building layout); 5) air traffic control (radiotelephony and its instrumentation, air traffic rules and regulations, navigation.); 6) airlines (world airlines and their logos, names, codes, airline management, cabin service, aircraft types, and flight safety); 7) aeronautical science and technology (avionics, navigation technology, aerodynamics, mechanics, power plant.); 8) miscellaneous (meteorology, medication and psychology for pilots and astronauts, environment protection: noise, emission, bio-fuel.). An EAP instructor is not expected to expertise in all vocabulary in the above mentioned domains, he can not do that! His job is to 
apply English lexicology into aeronautical vocabulary sorting and teaching in the context (course) of aeronautical English, and to explain certain terminologies or phraseologies in a specifically chosen context that he has comprehended.

Aeronautical English terminology is an inseparable part of aeronautical English vocabulary, it refers to a technical term or vocabulary, i.e. a collection of terms which has a certain coherence because the terms belong to a single subject area. The conceptual system-underlying terms belonging to a subject field show such a close generic, hierarchical or associative relationship that it is impossible to regard them as common words belonging to the general vocabulary of the layperson. To have a systematic recognition of aeronautical/aviation English terminology, we need to distinguish between different types of terminology because they need different focus and treatment according to students' different aims of learning. The basic terminological relations include equilent relation (see Figure 1), hierarchical relation (see Figure 2) and associative relation.

\section{Phonetic Phraseology in Radiotelephony}

Spoken vocabulary appears especially important in air communications, it is often the result of combining phonetics with certain specific information, or phonetic transcription phrase- ology. The terms convey with them specific meanings, and can be further extended into the field of aeronautical/aviation lexicology. Take "WILCO" for example, it is special because it is a phonetic combination of "we'll comply". Spoken vocabulary in aeronautical/aviation English may include the phonetic forms of alphabetics and numerics along with some frequently and normally used terms. The following are phraseologies used in RT communications along with their meanings and Chinese equivalents:

- ACKNOWLEDGE: Let me know that you have received and understood this message. Its Chinese equivalent is "qíng rèn shōu".

- APPROVED: Permission for proposed action granted. Its Chinese equivalent is "tóng yì".

- CANCEL: Annul the previously transmitted clearance. Its Chinese equivalent is "qú xiāo".

- CORRECTION: An error has been made in this transmission (or message indicated) the correct version is ... Its Chinese equivalent is "gēng zhèng".

- GO AHEAD: Proceed with your message. Its Chinese equivalent is "qǐng jiăng".

- ROGER: I have received all of your last transmission. Its Chinese equivalent is "shōu dào".

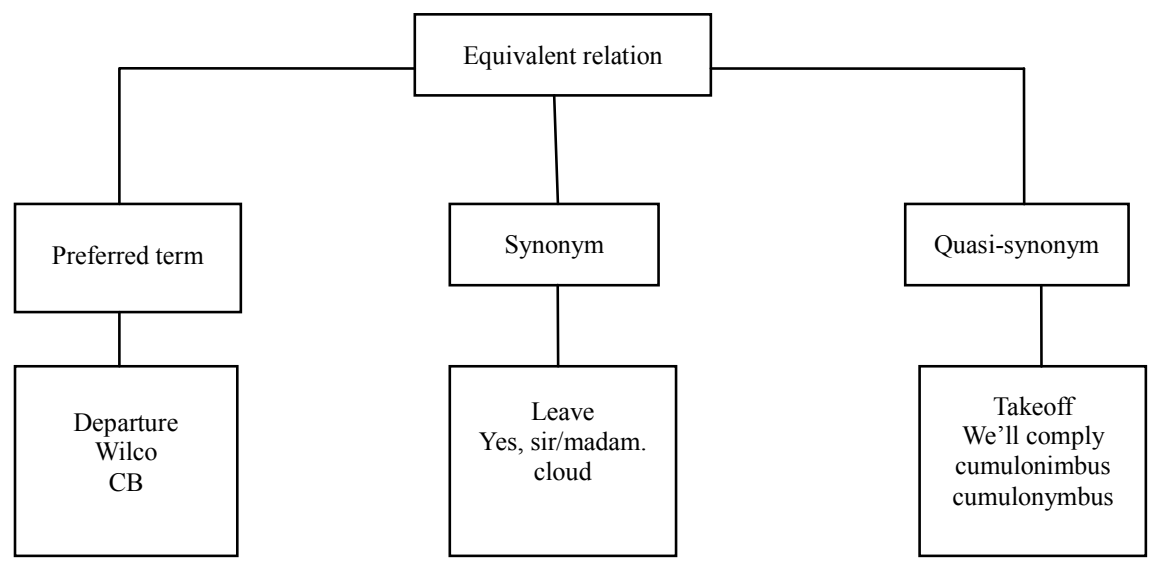

Figure 1.

Equivalent relation.

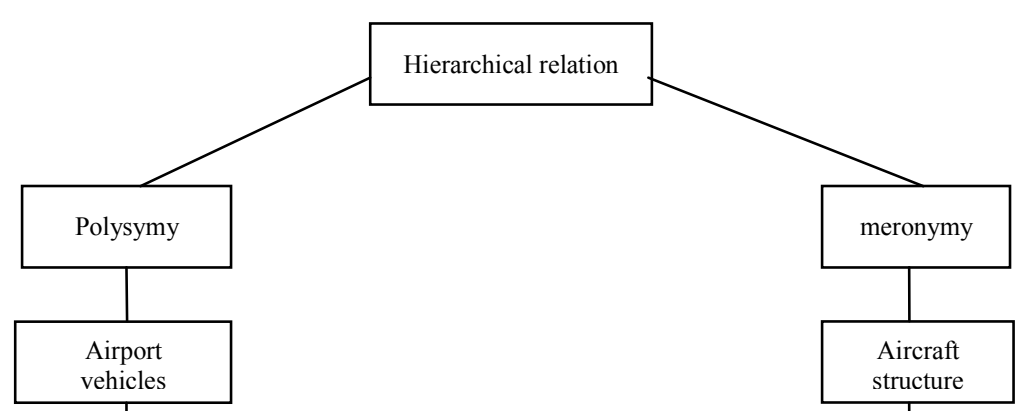

Shuttle, tow bar, tractor, fork lift truck, ramp, sweeper, snow blower, ambulance, ice-melter, refueler, catering truck...
Nose, fuselage, tail, propeller, windshield, cockpit, cabin, rudder, stablizer, elevator, slat, spoiler, undercarriage, tyre, ... 
- STANDBY: Wait and I will call you. Its Chinese equivalent is "děngdài". There are quite a number of such words and expressions in RT language. The accurate use of the spoken vocabulary does play an important role in air communication.

$\begin{array}{cc}\text { WORDS WITH TWO OR } & \text { SYNONYMS WITH } \\ \text { MORE SYLLABLES } & \text { ONLY ONE SYLLABLE } \\ \text { Terminate } & \text { stop } \\ \text { affirmative } & \text { yes } \\ \text { negative } & \text { no } \\ \text { descend } & \text { go down } \\ \text { monitor } & \text { mind } \\ \text { commence } & \text { start } \\ \text { request } & \text { ask } \\ \text { report } & \text { tell } \\ \text { contact } & \text { call }\end{array}$

Compared with its synonyms which only have one syllable, word with two or more syllables has its own advantages on decreasing the fuzziness in RT English.

\section{Technical, Semi-Technical and General Lexicology}

Technical lexicology has specialized and restricted meanings in certain disciplines and may vary in meaning across disciplines, while semi-technical lexicology is used in general language but has a higher frequency of occurrence in specific and technical description and discussion (Dudley-Evans \& St John, 1998: p. 83). Aeronautical/aviation English instructors will unavoidably come across technical lexicology in language instruction. His job is to assess the importance of such words in accordance with learners' specialty, and decide if they should be treated as technical, semi-technical or general words, and guide the English learners to grasp, recognize or identify them. The following text illustrates the difference between these types of lexicology.

... A line drawn from the leading edge to the trailing edge of an airfoil is referred to as the chord line. The camber of an airfoil is the curve of its surface. On general aviation training aircraft, the upper camber is usually more pronounced than the lower camber. Any object moving through the air encounters a relative wind. This wind is always parallel to and opposite the flight path. The angle formed between the relative wind and the chord line is called the angle of attack. The principle behind lift was discovered by a Swiss physicist, named Bernoulli, when he observed what happened to air as it passed through a tube. The principle simply states that as the velocity of a fluid or gas increases, its pressure decreases. He also found that with a constant velocity, the pressure of the air remains the same at both ends of the tube. If a constriction is placed in the middle of the tube, the same amount of air has to go through a smaller area. This increases the velocity and decreases the pressure. (excerpt from Basics of Aerodynamics).

Technical lexicology: leading edge; trailing edge; airfoil; chord line; camber; angle of attack; Bernoulli principle;

Semi-technical lexicology: velocity; fluid; pressure; constriction; tube;

General lexicology: encounter; pronounced; constant; increase; decrease.

For students of aircraft engineering specialty, the lexicology in aircraft stucture is both core and technical. So it is a must for them to grasp these words. For example, an airframe structurally consists of fore, middle and rear parts for which there are specific words or terms: In cockpit, there are control system and instrument system, the former includes pedals and joysticks that control the movement of the aircraft, such as yaw, pitch and roll. The later includes altimeter, attitude indicator, airspeed indicator, fuel gauge, variometer, gyroscope and magnetic compass that offer data information to pilots. In cabin, there are galley, trolley, toilet, interior fittings, floor, ceiling, lighting system, air-conditioning, intercom, oxygen masks, emergency slide, aisle, compartment, jump seat, life vest, locker, window, window-blind/shade, seat belt, armrest; emergency exit, fire extinguisher, gust wind lock that cabin attendants need to grasp in EAP vocabulary learning. In the middle part, especially the aircraft wings, there are words like slat, flap, aileron, leading/trailing edge, flaperon; wingtips; rib, spar, spoilers, stringer, dihedral. In rear part, there are words like empennage, fin-rudder, and stabilizer-elevator that should be mastered by students majoring in aircraft engineering or even flying techniques. Of course, it may take some time for an EAP instructor to acquaint himself with the chosen text and vocabulary before his teaching activities.

\section{Aviation Abbreviations}

With the rapid development of science and technology in the aeronautical field, more and more new words or terms pop out, and information on this aspect is up to minute. Words like astronaut, cosmonaut, taikonaut keep appearing day and night. Therefore, the teaching of lexicology in aeronautical and/or aviation industry is a challenge for us language practitioners. To help our students/trainees grasp more words and terms like this, we can seek aids from lexicology. Newly coined words are a trend to vocabulary growth in this field. The various ways of word-formation in lexicology can be well applied to the acquaintance of aviation terminology. Abbreviation is a common way of word formation in aeronautical or aviation language. It can be further divided into initialisms and acronyms (see Table 1).

An acronym is an abbreviation coined from the initial letter of each successive word in a term or phrase. In general, an

Table 1.

Initialisms and acronyms.

\begin{tabular}{cc}
\hline AIA & Aerospace Industries Association of America \\
CAA & Civil Aeronautics Administration \\
CAB* & Civil Aeronautics Board \\
FAA & Federal Aviation Administration \\
IATA* & International Air Transport Association \\
ICAO* & International Civil Aviation Organization \\
GCSS & Global Communication Satellite System \\
GPS & Global Positioning System \\
ILS & Instrument Landing System \\
SONAR* & sound navigation and ranging \\
DACOS* & data communication operating system \\
PAPI* & Precision-Approach Path Indicator \\
SPOT* & satellite positioning and tracking \\
MAD* & magnetic airborne detector \\
VASI* & Visualoph Slope Indicator \\
\hline
\end{tabular}


acronym made up solely from the first letter of the major words in the expanded form is rendered in all capital letters (NATO from North Atlantic Treaty Organization; but there are exceptions, such as ASEAN for Association of Southeast Asian Nations). In general, an acronym made up of more than the first letter of the major words in the expanded form is rendered with only an initial capital letter (Comsat from Communications Satellite Corporation. Hybrid forms are sometimes used to distinguish between initially identical terms (WTO: WTrO for World Trade Organization and WToO for World Tourism Organization). As the above table is concerned, those labeled with asterisk are words that can be pronounced as ordinary words, they are usually called acronyms. Those without asterisk labels are called initialisms in lexicology, they are read out letter by letter in the alphabetic order of the word.

\section{Experimental Methods of Aeronautical English Vocabulary Instruction in the Chinese Context}

The ex-president of ICAEA (International Civil Aviation English Association) Fiona A Robertson pointed out, while ground to air communication has been developing, so has the general language training process. This has moved from the grammar-translation approach through many different phases, the audio-lingual, audio-visual, structural, notional-functional, communicative, task based, lexical, EAP and needs analyses. The modern language teacher has a whole panoply of methodologies to choose from, many of which spring from advances in applied linguistics. Since aeronautical English lexicology consists of words and expressions from a large variety of fields, we must first be sure of our target students, their English level, their major and their needs. Aeronautical materials have been collected and analyzed for the teaching of aeronautical English lexicology in the Chinese context, such as aviation English project publication series: An Engish Course for Cabin Attendance, An English Course for Air Transportation, An English Course for Air Navigation, Public Avation English Through Reading, An English Course for Avionics, An English Course for Aircraft Maintenance. Besides, there are Miscellaneous aeronautical/aviation English course materials and aviation related video clips. As far as lexicology is concerned, six methods, including some traditional ones, are being used and recommended in the process of EAP instruction.

1) Phonetic method. Aviation phonetics is a part of the curriculum in EAP. On the basis of learning international phonetics systematically, learners will focus on aviation phonetics. These include the reading of numbers, alphabets, time, code of airport, air pressure and aircraft type, etc. For example, in English radiotelephony " 3 " is read out /TREE/ instead of / $\theta$ ri:/ as usual, "4" is read out /FOW-er/, "9" is read out /NIN-er/ instead of /nain/ as usual, because, to pronounce the sound $/ \theta /$, we have to put the tongue between the teeth, in addition, it is voiceless and this makes it difficult to be heard by the listener in communication, so the $/ \theta /$ sound is replaced by alveolar and plosive / $\mathrm{t} /$ in air communication, and the word "thousand" is pronounced as /TOU-SAND/. Therefore / $\mathrm{tr} /$ is likely to replace $/ \theta r /$ in this case with the consideration of efficiency and clarity. The pronunciation of the number "4" gets easily confused with that of the preposition "for", so the vowel /er/ is added (/FOWer/) to distinguish the two sounds. In pronouncing number "9", the second $/ \mathrm{n} /$ sound in /nain/ is a nasal and this makes it difficult to be heard too, so it would be safer and easier to be heard if we read it as /NIN-er/, with a vowel /er/ added to it. Phonetic method will help us effectively grasp aeronautical English words for practical purposes.

2) Context and illustration method.

Good students often use context clues to determine the meanings of unfamiliar words, if they are available in the text. They can locate other words and phrases in a passage that give clues about what an unknown word means. Struggling students who do not do this should be given direct instruction in how to effectively look for clues or definitions. The clues may be any of the following types of information embedded in the text: definition, restatement, example, comparison or contrast, description, synonym or antonym. In classroom activities, we may use the words, sentences, or paragraph(s) surrounding the unknown word to help determine its meaning. Sometimes illustration provides a considerable amount of information about the meaning of an unknown word. For example, after analyzing the structure and identifying different parts of an aircraft, students are then required to describe these different parts along with their functions (see Figure 3).

3) Word analysis method. English lexicology shows that there are at least 8 ways of word formation: compounding, derivation, blending, abbreviation, borrowing, onomatopoeia, conversion, and clipping. The majority of English words have been created through the combination of morphemic elements, that is, compounding and affixation (derivation). Root is the most important word element from which most of the meaning is derived, and it carries the majority of the denotative or dictionary meaning. Prefixes are those elements added to roots at the beginning of a word while suffixes at the end. Affixation changes the semantic and grammatical meanings of a word respectively. A knowledge of affixes (i.e. prefixes and suffixes) and roots has many values for learners of English. If learners understand how this combinatorial process works, they possess one of the most powerful understandings necessary for lexicology growth (Anderson \& Freebody, 1981: pp. 77-117). Take affixation for example, while interpreting the word intercommunication, we may 1) analyze its lexical formation: prefix + root: inter + communication; with more such words as interphone, intersection, intervention, etc., 2) clip it to a shorter form: intercom, 3) find out its related words: handset, broadcast, loudspeaker, megaphone, microphone, announcement, chime, etc., 4) associate it with prefabricate chunks: PA (passenger address) system, crew call system, lavatory call system, pushto-talk switch, PSU (passenger service unit), etc.

Another example is blending, for example, avionics $=$ Aviation + electronics;

ballute $=$ balloon + parachute;

comint $=$ communications + intelligence;

comsat $=$ communications + satellite;

heliport $=$ helicopter + airport;

helipad $=$ helicopter + pad;

avigator $=$ aviation + navigator;

flaperon $=$ flap + aileron;

altiport $=$ altitude + airport;

lidar $=$ light + radar;

hijack $=$ high + jack;

airtel $=$ airport + hotel .

Research shows that students can be taught strategic behaviors to improve their ability to learn the meaning of words (Kuhn \& Stahl, 1998). While skills such as application of morphological clues, reference works, and spelling clues to word meanings are all useful, they become more powerful and functional when combined with the use of context clues in a deliberate strategy. 


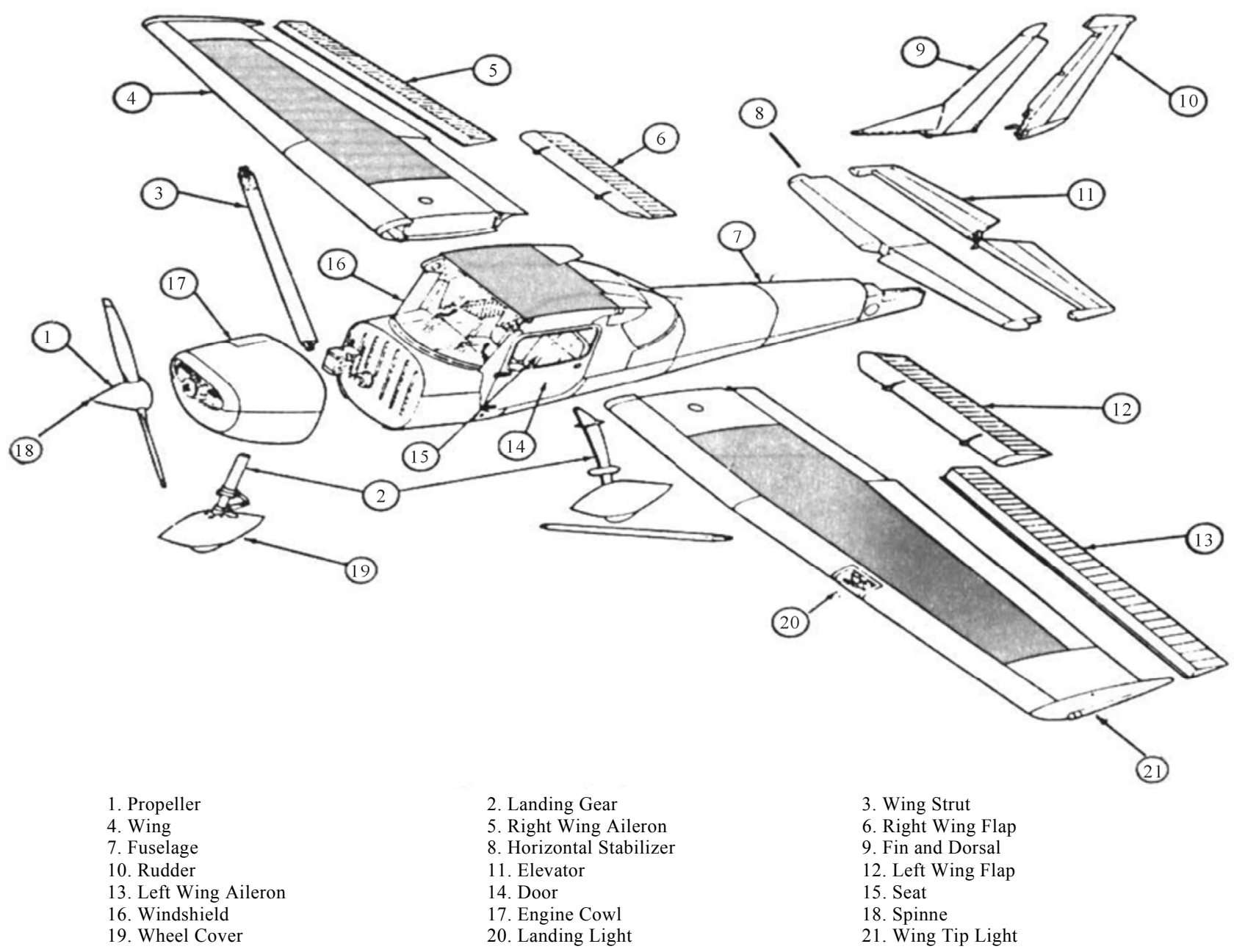

Figure 3.

The main parts of an airplane.

4) Mnemonic aids. Different people have different capacity of memory. Some people can remember a new word by reciting once or twice, while some others need more times. So, good mnemonic aids can help save time and improve efficiency. Most widely used memory aids are imagery and keywords. Imagery is a way in which learners remember something through images or pictures rather than words. Imagery is best used when learning more concrete words. Using keywords means to think of a catchy sentence or phrase that is related to the unknown word in some way.

5) Personal vocabulary notes. Besides those basic strategies for vocabulary acquisition, we teach our students to use some other tactics. Personal Vocabulary Notes (PVN) is another way of enlarging students' vocabulary in a personalized style that helps them become autonomous learners. The basic activity of PVN is straightforward. Students are encouraged to write words in their native language when they do not know how to say the English word.

- Give students a daily journal or PVN note paper to record vocabulary items. (PVN: if you do not know an English word, write the native language, show you partner, communicate, and then check the English later).

- Tell students that the English language is preferred in class.

- Engage students in some kind of fluency activity and encourage them to write words in native language if they find it hard to express in English.

- Ask the students to look up their PVN and find the English translations. They then should write sentences using their PVN.

- The teacher collects the PVN, checks it, and hands it back in the following class.

- Students keep a section in their notebook for PVN and do follow up activities with it such as peer teaching and review activities.

6) Knowledge-oriented lexicology instruction. Students are required to memorize these specific terms and be able to explain them orally. This method is not confined to lexical instruction, but special terminologies. For example:

EICAS/ECAM: The Engine Indication and Crew Alerting System (for Boeing) or Electronic Centralized Aircraft Monitor (for Airbus) will allow the pilot to monitor the following information: values for $\mathrm{N} 1, \mathrm{~N} 2$ and $\mathrm{N} 3$, fuel temperature, fuel flow, the electrical system, cockpit or cabin temperature and pressure, control surfaces. The pilot may select display of information by means of button press.

FMS: The Flight Management System/Control Unit may be used by the pilot to enter and check for the following information: flight plan, speed control, navigation control.

Manoeuvring area: The part of an aerodrome provided for the take-off and landing of aircraft and for the movement of 
aircraft on the surface, excluding the apron and any part of the aerodrome provided for the maintenance of aircraft.

Knowledge-oriented lexicology instruction is more suitable for aeronautical English learners in a content-centered specialty. No single individual can grasp the whole English vocabulary. Many EAP learners have realized this point and paradoxically have been discouraged. To teach students aeronautical English vocabulary, we need to put these EAP words or terminologies into language context. Therefore material selection is of crucial importance. Many texts are excerpted from operation manuals of different types of aircraft with a focus on lexicology in addition to flight operation knowledge. Lexicology is thus classified into different categories and involved in its corresponding context. In the basics of aerodynamics, for example, students are required to fill in the blanks according to their basic aerodynamic knowledge or the video clips provided:

- There are four forces acting on an airplane in flight. These forces are (lift, thrust, drag, gravity) and

- A line drawn from the leading edge to the trailing edge in an airfoil is called the (chord line)

- The (camber)

- It is important to note that an airplane whenever the critical angle of attack is exceeded, which can occur in any flight attitude and at any airspeed (stalls).

In just the same way, we may apply lexicology in vocabulary instruction in emergency situations, words and terminologies can be put into different contexts like decompression, water leakage, cabin fire and dangerous goods. After we finish the text, students are asked to speak out the special terms or words of cabin equipment. For example:

Symptoms of hypoxia: dizziness, nausea, blurred vision, slurred speech;

Emergency equipment for cabin fire: oxygen mask, PBE (protective breathing equipment), smoke goggle, fire-proof glove, water/Halon extinguisher;

Emergency equipment for ditching: life vest, life raft, crash axe

7) translation method. Translation method will help students not only to learn aeronautical terms in bilingual languages but also to consolidate what they have learnt. Most EFL teachers may appeal to this method in their lexicology instruction.
Mother tongue equivalents may serve as a hint to remind students of the English term they have learnt (see Table 2).

\section{Aeronautical English Vocabulary Teaching Cannot Be Separated from Aviation Culture}

While reading aeronautical or aviation materials we often come across proper names, aircraft types or makes, abbreviations of organizations, clubs, codes, technology systems, airlines and airports, etc which hardly appear in dictionaries. These terms or expressions are part of aviation culture or history. Traditional vocabulary teaching method seems more concerned with the pronunciation and literal sense of an individual word. The superficial meaning of a word should not be our focus, as it is time-consuming to nod over it while totally neglecting its cultural connotations.

When learners of the English language reach an intermediate level, they may find that collocation is something difficult to grasp. From lexical and semantic point of view, collocation can be considered as the third step of mastering the English language:

basic words $\rightarrow$ phrases and idioms $\rightarrow$ collocations $\rightarrow$ complete sentences.

This is equally true with Aviation English (not just confined to RTFE). When students have learned quite a number of words and expressions, they come into the problem of collocation. Therefore, it is the teacher's responsibility to help them find out the rules and regularities of collocating words and phrases, especially with specialty lexicology. Meanwhile we must bear in mind to explain them in EAP. For example:

- black box: The flight recorder, as on a military or commercial aircraft, that documents preflight checks, in-flight procedures, and the landing (hēixiázi);

- sniffer dog: Dog whose work is to sniffle the drugs, especially in Customs (xiù tàn quăn);

- base leg: A flight path at right angles to the landing runway off its approach end. The base leg (sì biān) normally extends from the downwind leg to the intersection of the extended runway centerline. Similarly, the equivalents of downwind leg, crosswind leg and upwind leg in Chinese are sān biān, liăng biān and yī biān.

Collocation training can help students realize the peculiarity

Table 2.

English and Chinese terms in power plant system.

\begin{tabular}{|c|c|c|c|c|c|}
\hline English terms & $\begin{array}{l}\text { Mother tongue } \\
\text { (Chinese pin yin) }\end{array}$ & English terms & $\begin{array}{l}\text { Mother tongue } \\
\text { (Chinese pin yin) }\end{array}$ & English terms & $\begin{array}{l}\text { Mother tongue } \\
\text { (Chinese pin yin) }\end{array}$ \\
\hline nacelle (cowl) & Yín qīng duăn cāng & spinnner & luó xuán zhuàn zi & pod & fā dòng jī diào cāng \\
\hline air inlet or intake & jìn qì dào & $\begin{array}{l}\text { bird, water } \\
\text { ingestion }\end{array}$ & fā dòng jī xī rù niăo, shuǐ & foreign object damage & Wài lái wù sǔn shāng \\
\hline fan & Fēng shàn & windmill & Fēng chē & rotor & zhuàn zi \\
\hline fan blades & Fēng shàn yè piàn & propeller & luó xuán jiăng & propeller blade & jiăng yè \\
\hline propulsor & tuī jìn qì & reduction gearbox & Jiăn sù qì & LP and HP compressors & dī yā he gāo yā yā suò jī \\
\hline $\begin{array}{l}\text { annular } \\
\text { combustor }\end{array}$ & $\begin{array}{l}\text { huán xíng rán } \\
\text { shāo shì }\end{array}$ & $\begin{array}{l}\text { multiple-can } \\
\text { combustor }\end{array}$ & guăn xíng rán shāo shì & can-annular combustor & guăn huán rán shāo shì \\
\hline $\begin{array}{l}\text { reverse-flow annular } \\
\text { combustor }\end{array}$ & $\begin{array}{l}\text { huí líu shì huán xíng } \\
\text { rán shāo shì }\end{array}$ & turbocharger & wō lún zēng yā qì & turbine wheel & wō lún dao xiang qi \\
\hline
\end{tabular}


of EAP so that they get into the habit of speaking English in its specialty domain and using terminologies at proper times. In order to overcome "cultural distance", learners may be exposed to FL texts of popular literature, such as "aircraft safety culture", manuals of Airbus/Boeing series, introduction to airlines in English speaking countries. Learners can easily recognize the social stereotypes on which these texts are based. Thus, instead of fixed typologies of isolated cultural facts, learners learn to match checklists of cognitive typologies or universal networks of meaning with specific texts.

\section{Conclusion}

Aeronautical English lexicology teaching is actually a study and interpretation of aviation language and culture in depth, a process of telling students how to analyse word formation, how to employ association and connection, how to get involved in aviation culture. The learner's mother tongue, the lexicology of the target language he has acquired, the encyclopedic and word knowledge may all be a stimulus in the storage and retrieval of new word information. Different levels of word information will build an associative network, which helps to consolidate the semantic networks of mental lexicon.

The proper usage of teaching materials, classroom activities and correct teaching methods targeted at different groups of students are all perceived as enjoyable ways to teach aeronautical English lexicology. Theoretically, the more words are analyzed either phonologically, semantically or comprehensively, the more they are enriched by associations rendered by learners, the longer they will be stored in memory. For instance, in the process of memorizing a group of structurally related words like dynamic (adj..), dynamics (n.), aerodynamics (n.), aero-astro-dynamics (n.), EAP learners can associatively memorize them with derivational knowledge. Learners are encouraged to make their own lexical associations when learning new lexicology. As Hulstijn (2001) has stated, to some extent it can transform the lexicology learning task from uninspired drudgery into newfound delight. In fact, aeronautical lexicology teaching strategy is greatly concerned with quantity and quality of lexicology knowledge. EAP instructors should realize the significance of aeronautical lexicology teaching and have it penetrated into EAP teaching activities.

\section{References}

Anderson, R. C., \& Freebody, P. (1981). Vocabulary knowledge. In J. Guthrie (Ed.), Comprehension and Teaching: Research Reviews (pp. 77-117). Newark, DE: International Reading Association.

Blue, G. (1988). Individualising academic writing tuition. In P. Robinson (Ed.), Academic Writing: Process and Product (pp. 129-148). London: MET and British Council.

Chall, J. S., \& Jacobs, V. A. (2003). Poor children's fourth-grade slump. American Educator, 27, 14-15.

Dudley-Evans, T., \& St John, M. J. (1998). Developments in English for specific purposes. Cambridge: CUP.

Hulstijn, J. (2001). Mnemonic methods in foreign language vocabulary learning: Theoretical considerations and pedagogical implications. In J. Coady and T. Huckin (Eds.), Second Language Vocabulary Acquisition (p. 220). Shanghai: Shanghai Foreign Language Education Press.

Kuhn, M. R., \& Stahl, S. A. (1998). Teaching children to learn word meanings from context: A synthesis and some questions. Journal of Literacy Research, 30, 119-138.

doi:10.1080/10862969809547983

\section{Appendix I. Survey Result (Frustrations in Acquiring Language Skills)}

\begin{tabular}{ccccc}
\hline skills/items & Vocabulary & Grammar/Structure & Accent/Speed & Culture \\
\hline Listening \%: & 50 & 12 & 30 & 8 \\
Speaking \%: & 44 & 18 & 18 & 20 \\
Reading \%: & 79 & 8 & 6 & 7 \\
writing \%: & 48 & 32 & 8 & 12 \\
\hline
\end{tabular}

